\title{
The Global Distribution of Trademarks: Some Stylized Facts
}

\author{
By Eugenia Baroncelli, Carsten Fink and Beata Smarzynska Javorcik ${ }^{*}$
}

\begin{abstract}
Trademarks are words, signs, symbols or combinations thereof that identify goods as manufactured by a particular person or a company, therefore allowing consumers to distinguish between goods originating in different sources. Trademarks belong to the wider family of intellectual property rights (IPRs), and once registered benefit from legal protection against unauthorized use by entities other than the legal owner.
\end{abstract}

While some suggest that cross-border registrations of IPRs may be associated with welfare transfers from developing to industrial countries, surprisingly little is known about an important component of the global IPR system, namely, the worldwide distribution of trademark registrations. This study provides the first step in filling this gap in the literature. Its purpose is to present some new stylized facts, which emerge from the analysis of a dataset compiled by the authors based on the statistical information published by the World Intellectual Property Organization (WIPO). Questions of interest include the distribution of trademarks between countries of different income levels, the share of trademark registrations accounted for by foreign residents and its variation across different income groups, the extent to which poor countries participate in the international trademark system, and the distribution of registrations across different sectors of the economy.

The stylized facts presented in this paper indicate that the global distribution of trademarks is skewed toward high-income industrial countries. The data also suggest that trademark registrations are concentrated in research and development-intensive sectors such as pharmaceuticals, scientific equipment, and the chemical industry.

World Bank Policy Research Working Paper 3270, April 2004

The Policy Research Working Paper Series disseminates the findings of work in progress to encourage the exchange of ideas about development issues. An objective of the series is to get the findings out quickly, even if the presentations are less than fully polished. The papers carry the names of the authors and should be cited accordingly. The findings, interpretations, and conclusions expressed in this paper are entirely those of the authors. They do not necessarily represent the view of the World Bank, its Executive Directors, or the countries they represent. Policy Research Working Papers are available online at http://econ.worldbank.org.

\footnotetext{
* World Bank, 1818 H Street, NW, MSN MC3-303, Washington, DC, 20433. Tel. (202) 458-8485. Email: ebaroncelli@worldbank.org, cfink@worldbank.org, bsmarzynska@worldbank.org. We wish to thank Matthijs Geuze, William Guy, Walter Park, Bojan Pretnar, and Ernesto Rubio for valuable comments and suggestions.
} 


\section{Introduction}

Trademarks are words, signs, symbols or combinations thereof that identify goods as manufactured by a particular person or a company, therefore allowing consumers to distinguish between goods originating in different sources. When such signs and symbols are applied to services, we refer to them as service marks. The trademark system is designed, inter alia, to protect the reputational assets of a natural person or a legal entity and, therefore, provides incentives for investments in quality of goods and services sold on the market. ${ }^{1}$

Trademarks belong to the wider family of intellectual property rights (IPRs). Businesses and individuals register trademarks in special registers created and maintained by governments. Once registered, owners of trademarks benefit from legal protection against unauthorized use by third parties. ${ }^{2}$ Registration prevents the coexistence of confusingly similar trademarks and serves as proof of ownership, for example, in the case of legal disputes. While trademark laws and registers can be found in virtually every country, national regimes often differ markedly as to whether particular signs qualify as trademarks, the scope of protection, guidelines for avoiding confusing marks, registration costs, legal means available to fight infringement and other important details. ${ }^{3}$

While the commonly held view suggests that cross-border registrations of IPRs may be associated with welfare transfers from developing to industrial countries (see, for example, McCalman, 2001), surprisingly little is known about an important component of the global IPR system, namely, the worldwide distribution of trademark registrations. Despite the availability of data on trademark applications and registrations for a large number of countries, researchers have hardly paid any attention to this subject.

This study provides the first step in filling this gap in the literature. Its purpose is to present some new stylized facts, which emerge from the analysis of a dataset put together by the authors based on the statistical information published by the World Intellectual Property Organization (WIPO). The questions of interest include the distribution of trademarks between

\footnotetext{
${ }^{1}$ Note that trademarks are not necessarily restricted to goods of highest quality, they are merely designed to assure consumers of consistent quality. For a seminal review of the economic rationale of trademark protection, see Landes and Posner (1997).

${ }^{2}$ Some national legal systems provide for the protection of trademarks by virtue of their use and without registration. However, such legal systems often offer greater protection for trademarks upon registration.

${ }^{3}$ However, the legal process for registering trademarks is similar across countries.
} 
countries of different income levels, the share of trademark registrations accounted for by foreign residents and its variation across different income groups, the extent to which poor countries participate in the international trademark system, and the distribution of registrations across different sectors of the economy.

Understanding these issues is important for two reasons. First, they shed light on the global distribution of intellectual property ownership and thus possible welfare implications of a reform of the global IPR system. In particular, they help assess the economic implications of international agreements on trademark protection, most prominently the WTO's Agreement on Trade-Related Aspects of Intellectual Property Rights (TRIPS). Second, they provide evidence on how firms from different countries use trademarks as a way of investing in reputational assets, which, in turn, is an important factor in determining competitive processes and international trading patterns.

The paper is organized as follows. Section I provides a brief introduction into the trademark system, the key components of trademark laws, trademark administration and enforcement, and ways in which firms can obtain protection in foreign markets. Section II establishes the key stylized facts that emerge from an analysis of disaggregated data on trademark registrations. The final section concludes by comparing some stylized facts for trademarks and patents and discussing potential policy implications.

\section{The main features of the trademark system}

In order to receive protection for their trademarks, firms or individuals must file an application with a national intellectual property office. Upon payment of a fee, the trademark office examines whether the proposed signs, symbols or names are unique to the sectoral classes for which protection is sought and are not confusingly similar to already existing marks. ${ }^{4}$ If an application meets all the relevant criteria, the trademark is officially registered for a limited time period - typically 10 years. However, prior to expiration, trademark holders have the option of renewing their registration. Through continuing renewals, and absent any act or failure to act

\footnotetext{
${ }^{4}$ Note, however, that in the European Union and in virtually all Central and Eastern European countries, a distinction is made between so-called absolute and relative grounds for refusal of a trademark registration. Offices examine new trademarks applications only with respect to absolute grounds, i.e. distinctiveness, etc., but not with respect to similarity with existing marks, which is a relative ground. Consequently, an identical or confusingly similar trademark is refused to be registered only if a holder of an earlier identical or confusingly similar mark files an opposition.
} 
which might call the rights concerned into question, trademark registrations can virtually last forever. ${ }^{5}$

Trademark registration gives the trademark owners the exclusive right to commercially use the protected names or symbols, including licensing them to third parties. These exclusive rights are enforced by a country's judicial system. For example, in order to immediately stop infringing activities, such as the sale of counterfeit products, trademark holders can request seizures or preliminary injunctions through the court system. ${ }^{6}$ And if the claim of infringement is verified by trial, courts can demand a payment to be made to the legitimate title holder.

Trademark rights are territorial in nature, in the sense that each nation protects IPRs only insofar as these rights are exercised in the domestic economy. Since trademark holders may seek to market and sell their goods and services in foreign countries, there exists scope for cooperation between governments. A simple form of cooperation consists of establishing a mechanism that facilitates the process of registering trademarks in foreign countries. Such a mechanism has emerged in the form of regional trademark offices, where firms can register trademarks at a supranational level and thus obtain simultaneous protection in a number of jurisdictions. The three most prominent examples of such regional intellectual property offices are the European Union's Office for Harmonization in the Internal Market (OHIM), the African Intellectual Property Organization (OAPI), and the African Regional Industrial Property Organization (ARIPO).

Another international mechanism for registering trademarks has emerged through the conclusion of two treaties, namely the Madrid Agreement Concerning the International Registration of Marks (Madrid Agreement of 1891) and the Protocol Relating to the Madrid Agreement Concerning the International Registration of Marks (Madrid Protocol of 1989). The so-called Madrid system substantially reduces the administrative burden and transaction costs involved in registering trademarks and maintaining them in multiple countries by allowing an applicant to file one international application and designate the countries in which protection is

\footnotetext{
${ }^{5}$ A special case is when trademarks become part of the public domain. For example, the "Xerox" or "Walkman" trademarks were judged to have become part of the common vocabulary and the trademark holders were asked by certain jurisdictions - against a financial compensation - to give up their exclusive rights.

${ }^{6}$ When it is necessary to preserve the status quo prior to a trial, a court may issue a preliminary injunction or temporary restraining order ordering a party to carry out a specified activity, such as for instance, halting the production and distribution of goods infringing on exclusive trademark rights.
} 
sought. It is administered by the World Intellectual Property Organization headquartered in Geneva.

A deeper form of international cooperation takes the form of international agreements that provide for some form of harmonized minimum standards of trademark laws and administrative and enforcement procedures. The rationale for such agreements is to minimize conflicts that can arise if domestic IPRs regulations discriminate against foreign nationals or if standards of protection are weaker abroad than they are at home.

Most prominently, the Paris Convention for the Protection of Industrial Property (Paris Convention of 1883), to which 164 countries are members, contains, among other things, substantive provisions regarding national treatment (each contracting state must grant the same protection to nationals of other contracting states that it grants to its own nationals), a sixthmonth right of priority (the filing date of a first-filed regular trademark application in one contracting state may be claimed in subsequent applications filed in other contracting states within six months of that first filing date).

The Agreement on Trade-Related Aspects of Intellectual Property Rights (TRIPS) of 1994, which was negotiated as part of the Uruguay Round of global trade negotiations and came into force in 1996, builds upon the pre-existing IPR conventions. It sets more stringent minimum standards, among other things, for trademark protection and lays down procedures and remedies to be implemented in national laws for IPRs enforcement, which members of the World Trade Organization (WTO) are required to meet. Countries must extend protection to internationally recognized trademarks in order to prevent their speculative registration and fraudulent use. It is important to recognize, however, that in many countries, the trademark standards negotiated under TRIPS were already part of pre-TRIPS law and jurisprudence (Watal, 2001).

With regard to enforcement, TRIPS sets standards on, among other things, enforcement procedures, the treatment of evidence, injunctive relief, damages, and provisional and border measures. At the same time, addressing concerns of some developing country WTO members, Article 41.5 makes clear that countries do not need to "put in place a judicial system for the enforcement of intellectual property rights distinct from that for the enforcement of law in general".

Finally, the emergence of the Internet has led to another important form of international cooperation. A special resolution by the Internet Corporation for Assigned Names and Numbers 
(ICANN) established in 1999 the WIPO domain name dispute resolution body, which provides holders of trademark rights with an administrative mechanism to challenge the bad-faith registration of Internet domain names that correspond to those trademarks. The arbitration of disputes between private parties by an inter-governmental organization, such as WIPO, arguably represents the deepest form of international cooperation on intellectual property.

\section{An analysis of disaggregated data on trademark registrations}

Trademark applications and registrations can be traced through operational statistics compiled by national intellectual property offices. These statistics can provide information on the cross-country and sectoral distribution of trademarks, as well as on the use of international agreements, such as the Madrid Protocol. At the international level, WIPO compiles statistical tables that report country-specific application and registration data, relying on information supplied by national and regional intellectual property offices. ${ }^{7}$

Using the published WIPO data, we created a database that serves as the basis for the summary statistics and stylized facts reported in this section. The database spans from 1994 to 1998 and covers more than 100 countries, although the availability of observations and degree of disaggregation varies substantially across countries. The annexes provide a detailed description of the methods employed in building the database, a list of all the variables available and a summary of the key information on sample composition by country income groups. ${ }^{8}$ Since the database contains information on registration, it is important to keep in mind that registrations refer to the annual flow of new trademarks, which may not necessarily be correlated with the stock of trademarks in force.

\section{Domestic versus foreign registrations}

Who accounts for a larger share of trademarks, domestic residents or foreign residents? Calculating the share of foreign trademark registrations in total registrations across different income groups, we find that

\footnotetext{
${ }^{7}$ It is important to recognize that there are many signs or brands used without being registered as trademarks. It is difficult to asses the ratio between non-registered and registered trademarks, but it is likely that in most developing countries this ratio is significantly higher than in developed countries.

${ }^{8}$ The database is available to researchers upon request.
} 
the majority of trademarks in high-income countries are registered by residents, while the situation is reversed in low-income countries, where a vast majority of trademarks are held by non-residents. The foreign share of registrations in middle-income countries lies between those observed in the high and low-income groups. ${ }^{9}$

As shown in Figure 1, foreign residents account for 34 percent of total trademark registrations in high-income countries. This compares to a foreign share of 46 percent for middle-income countries and 81 percent for low-income countries. These figures suggest that a higher level of development may be associated with generating more reputational assets, which lead to a greater dominance of domestic brands at home and a stronger presence of those brands in foreign markets.

Figure 1: Domestic versus foreign registrations, 1994-98

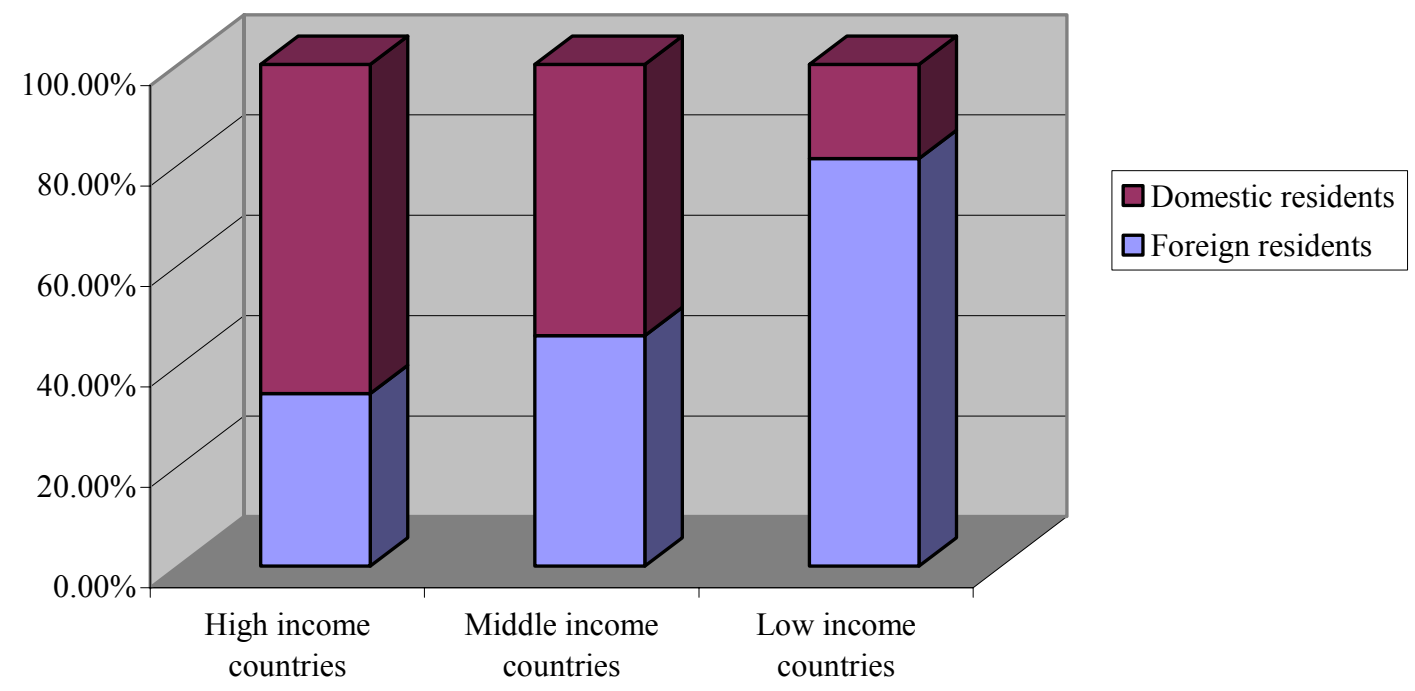

Notes: The shares shown are simple averages of annual shares over 1994-1998. Calculations are based on 95 countries in 1994 and 1995, 96 countries in 1996, 75 in 1997 and 74 in 1998.

To give a specific example. 217,333 trademarks were registered in the United Kingdom during 1994-98, of which 46.7 percent belonged to non-residents. During the same period, British entities registered 125,472 trademarks abroad which is 8.4 percent more than the number

\footnotetext{
${ }^{9}$ We used the World Bank Country Classification in assigning countries to different income groups. See http://www.worldbank.org/data/countryclass/classgroups.htm. High middle and low middle income countries have been lumped together as one middle income country group.
} 
registered by British residents at home (one should keep in mind that the figure on foreign registrations encompasses registrations of the same trademarks in multiple countries).

2. Where do foreign trademarks come from?

Further disaggregating foreign registrations by the country of origin of the trademark holder reveals that

in all three country groups, residents from high-income countries dominate foreign registrations, followed by residents from middle-income countries and low-income economies.

As shown in Table 1, registrations by foreign residents from high-income countries predominate in all three income groups, accounting for 91 percent in high-income countries, 84 percent in middle-income countries and 82 percent in low-income countries. Registrations by foreign residents from middle-income countries take a small share of total foreign registrations, representing 3, 6, and 8 percent in high, middle, and low-income countries, respectively. Residents of India - the only low-income source explicitly listed in the WIPO tables - have a negligible presence in foreign countries, making up only 0.2 percent of foreign registrations in (other) low-income countries, and only 0.1 percent in middle and high-income countries.

Table 1: Breakdown of foreign registrations, 1994-98

\begin{tabular}{lcccc}
\hline & \multicolumn{3}{c}{ Country of the entity registering a trademark } \\
\hline & $\begin{array}{c}\text { High-income } \\
\text { countries }\end{array}$ & $\begin{array}{c}\text { Middle-income } \\
\text { countries }\end{array}$ & $\begin{array}{c}\text { India } \\
\text { (Low-income) }\end{array}$ & Other countries \\
\hline Country where trademark is registered & & & & \\
High-income countries & $90.53 \%$ & $3.04 \%$ & $0.10 \%$ & $6.34 \%$ \\
Middle-income countries & $83.77 \%$ & $6.03 \%$ & $0.12 \%$ & $10.09 \%$ \\
Low-income countries & $82.35 \%$ & $7.96 \%$ & $0.17 \%$ & $9.52 \%$ \\
& & & & \\
\hline
\end{tabular}

Notes: The shares shown are simple averages of annual shares over 1994-1998. Calculations are based on 91 countries in 1994 and 1995, 92 countries in 1996, 73 in 1997 and 70 in 1998.

These shares, however, understate the presence of low and middle-income countries in foreign trademark registrations. The statistical tables published by WIPO report a residual category "other countries," which mostly consists of low and middle-income countries not 
explicitly listed in the tables. ${ }^{10}$ The category "other countries" accounted for 6 percent of foreign registrations in high-income countries and 10 percent in both low and middle-income countries. Nevertheless, even if we combined middle-income economies, India and "other countries," their overall share in total foreign registrations would not exceed 18 percent in low-income countries, and 16 and 9 percent in the middle and high-income groups, respectively.

Another way of showing that larger and richer countries tend to register more trademarks abroad is to plot the number of trademark registrations in foreign countries against the GDP level of the registering country. As illustrated in Figure 2 below, we find a strong positive correlation between the two series.

\section{Figure 2: GDP Level and the Number of Trademark Registrations Abroad}

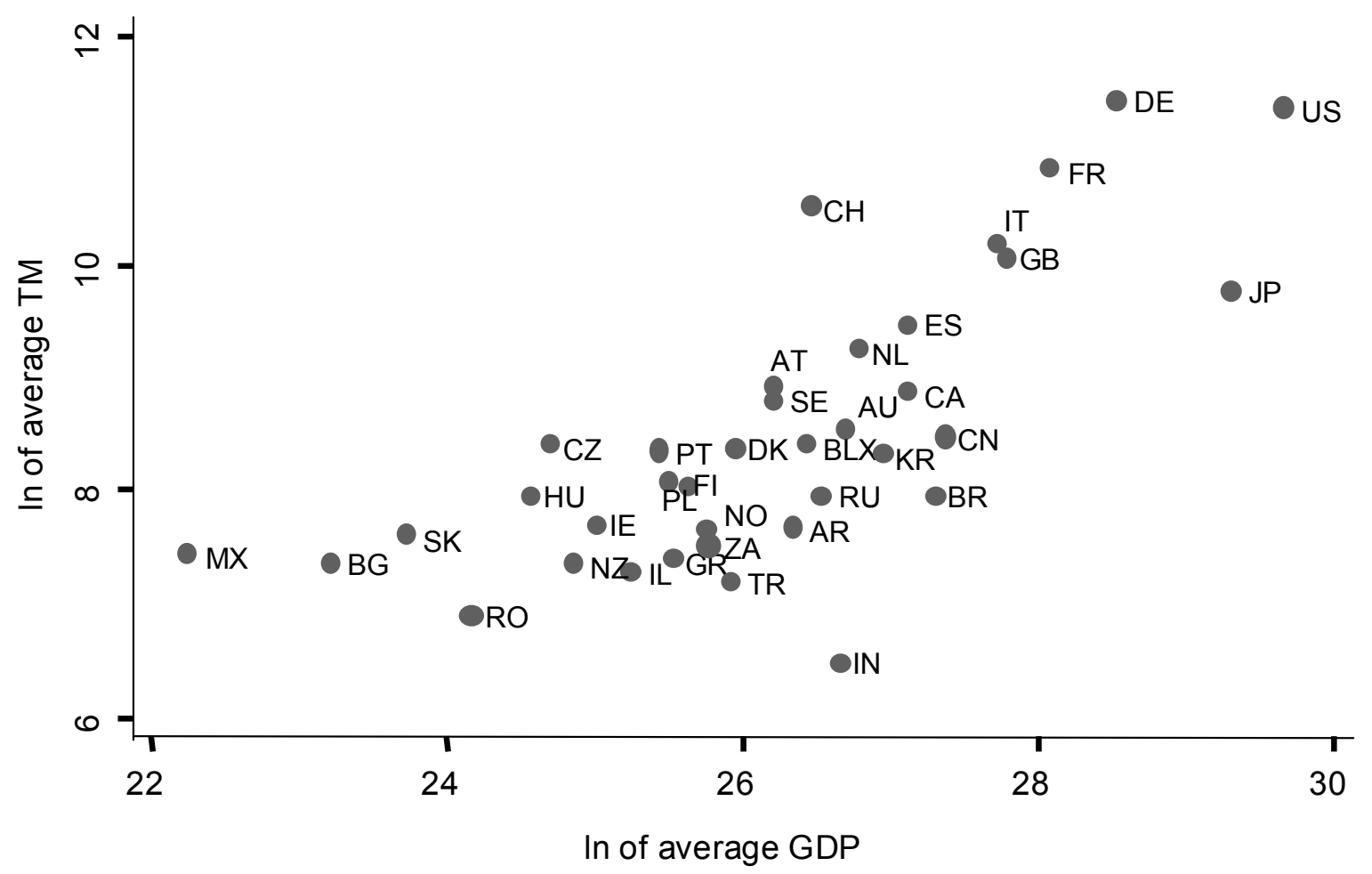

Notes: Both the GDP and the number of trademark registrations abroad are expressed as the natural logarithm of the average value for the 1994-98 period. GDP figures are in constant 1995 dollars.

\footnotetext{
${ }^{10}$ All major high income countries are explicitly listed in the WIPO tables.
} 
Firms have an incentive to register their trademarks in foreign markets where they sell or intend to sell their products. ${ }^{11}$ Thus we would expect shares of trademark registrations by applicants from different income groups to be related to the shares of imports coming from their group to the country where the registration takes place. Thus, in Table 2 we present import flows between the different income groups. We focus on the same set of countries included in Table 1, but present data for 1996 only (the year for which data was available for the largest number of countries in Table 1). Indeed, we find that the vast majority of imports entering low, middle and high-income economies originate in high-income countries. Recall that a vast majority of foreign trademarks registered there also come from high-income economies. ${ }^{12}$

Table 2: Import flows between income groups, 1996

\begin{tabular}{lccc}
\hline \multicolumn{3}{c}{ Exporter } \\
\hline Importer & High-income countries & Middle-income countries & India \\
High-income countries & $81.77 \%$ & $17.43 \%$ & $0.80 \%$ \\
Middle-income countries & $81.21 \%$ & $18.08 \%$ & $0.70 \%$ \\
Low-income countries & $60.71 \%$ & $38.41 \%$ & $0.89 \%$ \\
\hline
\end{tabular}

Source: Calculations derived from IMF, Direction of Trade Statistics, 1996. The sample is based on the same set of countries used for Table 1, which originally encompassed 92 importing countries and 39 exporting countries. However, two importing countries (Monaco and Andorra) and two exporting countries (Liechtenstein and Luxemburg) had to be excluded due to unavailability of bilateral trade data. Shares are calculated from c.i.f. valued import figures expressed in millions of US dollars.

Moreover, we find that

over the period 1994-1998, residents of middle-income countries have increased their share of foreign registrations in other middle-income as well as in low-income countries. At the same time residents from India - the only low-income source for which data are available-have increased their share of foreign registrations in high and middle- income countries.

\footnotetext{
${ }^{11}$ For an econometric analysis of the relationship between trade and trademark registrations see Fink, Javorcik and Spatareanu (2003).

${ }^{12}$ For both international trademark and trade flows, we find that middle-income countries make up a larger share of foreign trademark registrations in low than in (other) middle-income economies, with the difference being more pronounced in the case of the trade figures.
} 
Table 3 provides the annual breakdown of foreign registrations for the period 1994-1998 by income group of the registering party. To keep the information comparable across time, the sample is restricted to 53 countries for which that data for all years are available. Several patterns emerge. First, the share of foreign registrations by high-income countries in other highincome countries has fallen from 92.5 percent in 1994 to 89 percent in 1998, while middleincome country and what is lumped together as "other countries" were able to expand their respective shares. Moreover, the share of India — although still tiny — has more than doubled rising from 0.06 percent 1994 to 0.14 percent in 1998 .

Table 3: Foreign registrations broken down by income groups, annual shares

\begin{tabular}{|c|c|c|c|c|c|c|}
\hline $\begin{array}{c}\text { Foreign } \\
\text { registrations }\end{array}$ & Year & $\begin{array}{c}\text { By high-income } \\
\text { countries } \\
(\%)\end{array}$ & $\begin{array}{c}\text { By middle- } \\
\text { income } \\
\text { countries } \\
(\%)\end{array}$ & $\begin{array}{c}\text { By India } \\
(\%)\end{array}$ & $\begin{array}{c}\text { By "other } \\
\text { countries" } \\
(\%)\end{array}$ & $\begin{array}{c}\text { By all foreigners } \\
(\%)\end{array}$ \\
\hline \multirow{5}{*}{$\begin{array}{l}\text { In high } \\
\text { income } \\
\text { countries }\end{array}$} & 1994 & 92.51 & 2.23 & 0.06 & 5.20 & 100 \\
\hline & 1995 & 90.85 & 3.91 & 0.09 & 5.14 & 100 \\
\hline & 1996 & 90.97 & 2.60 & 0.11 & 6.33 & 100 \\
\hline & 1997 & 90.11 & 3.23 & 0.10 & 6.56 & 100 \\
\hline & 1998 & 89.11 & 3.44 & 0.14 & 7.30 & 100 \\
\hline \multirow{5}{*}{$\begin{array}{l}\text { In middle } \\
\text { income } \\
\text { countries }\end{array}$} & 1994 & 87.11 & 4.66 & 0.05 & 8.19 & 100 \\
\hline & 1995 & 86.78 & 4.53 & 0.08 & 8.60 & 100 \\
\hline & 1996 & 82.95 & 5.59 & 0.12 & 11.33 & 100 \\
\hline & 1997 & 82.68 & 7.89 & 0.13 & 9.30 & 100 \\
\hline & 1998 & 82.76 & 7.68 & 0.16 & 9.40 & 100 \\
\hline \multirow{5}{*}{$\begin{array}{c}\text { In low } \\
\text { income } \\
\text { countries }\end{array}$} & 1994 & 93.49 & 4.14 & 0.10 & 2.27 & 100 \\
\hline & 1995 & 88.30 & 6.04 & 0.04 & 5.62 & 100 \\
\hline & 1996 & 85.43 & 5.87 & 0.04 & 8.67 & 100 \\
\hline & 1997 & 79.67 & 10.78 & 0.03 & 9.51 & 100 \\
\hline & 1998 & 76.97 & 12.13 & 0.02 & 10.87 & 100 \\
\hline
\end{tabular}

Notes: For purposes of comparison, calculated shares only refer to 53 reporting countries, for which data in all 5 years are available.

The picture is similar in the middle-income group, where the share of foreign registrations by high-income countries fell from 87 to less than 83 percent in the time period under consideration. The increase in the share of middle-income countries themselves is relatively more pronounced, rising from 4.7 percent in 1994 to 7.7 percent in 1998. And a low-income economy, India, has more than tripled its share of foreign registrations in middle-income 
countries. As already pointed out, however, India's share remains very small, standing at only 0.16 percent in 1998 .

Finally, the most pronounced shift in foreign registration patterns seems to have taken place in low-income countries. The share of high-income countries dropped from 93 to 77 percent during the period in question, while middle-income countries and "other countries" tripled their shares from 4 to 12 percent and from 2.3 to 11 percent, respectively. In contrast to the patterns described for high and middle-income countries, the share of India in other lowincome countries declined continuously from 0.1 percent in 1994 to 0.02 percent in 1998 . The figures calculated for low-income countries should be interpreted with due caution, however, as they are based on only 7 reporting countries (Kyrgyzstan, Laos, Malawi, Mongolia, Republic of Moldova, Tajikistan, and Ukraine).

In sum, across all income groups high-income countries dominate trademark registrations by foreign residents. However, in recent years, trademark holders from middle-income countries have increased their presence in high and middle-income countries.

\section{Use of the Madrid system for international registrations}

The Madrid system offers a cost- and time-saving way of registering trademarks internationally. Over time, membership to the Madrid system has increased considerably, from 25 participating countries in 1985 to 66 member states in 2000, and 69 in 2002 (Figure 3). Membership has increased across all income groups. Between 1985 and 1995, the number of low-income parties increased from 4 to 16, the number of middle-income parties increased from 8 to 27 , and the number of high-income parties from 13 to $23 .{ }^{13}$ The widened participation in the Madrid system has enlarged the benefits of individual membership, as trademark holders can designate a greater number of foreign destinations through one Madrid application.

\footnotetext{
${ }^{13}$ It is interesting to note that large economies such as Canada, Japan, the United Kingdom, the United States have, so far, found the benefits of membership to be insufficient to accede to the Madrid system.
} 
Figure 3: Number of countries member to either Madrid Agreement or Madrid Protocol

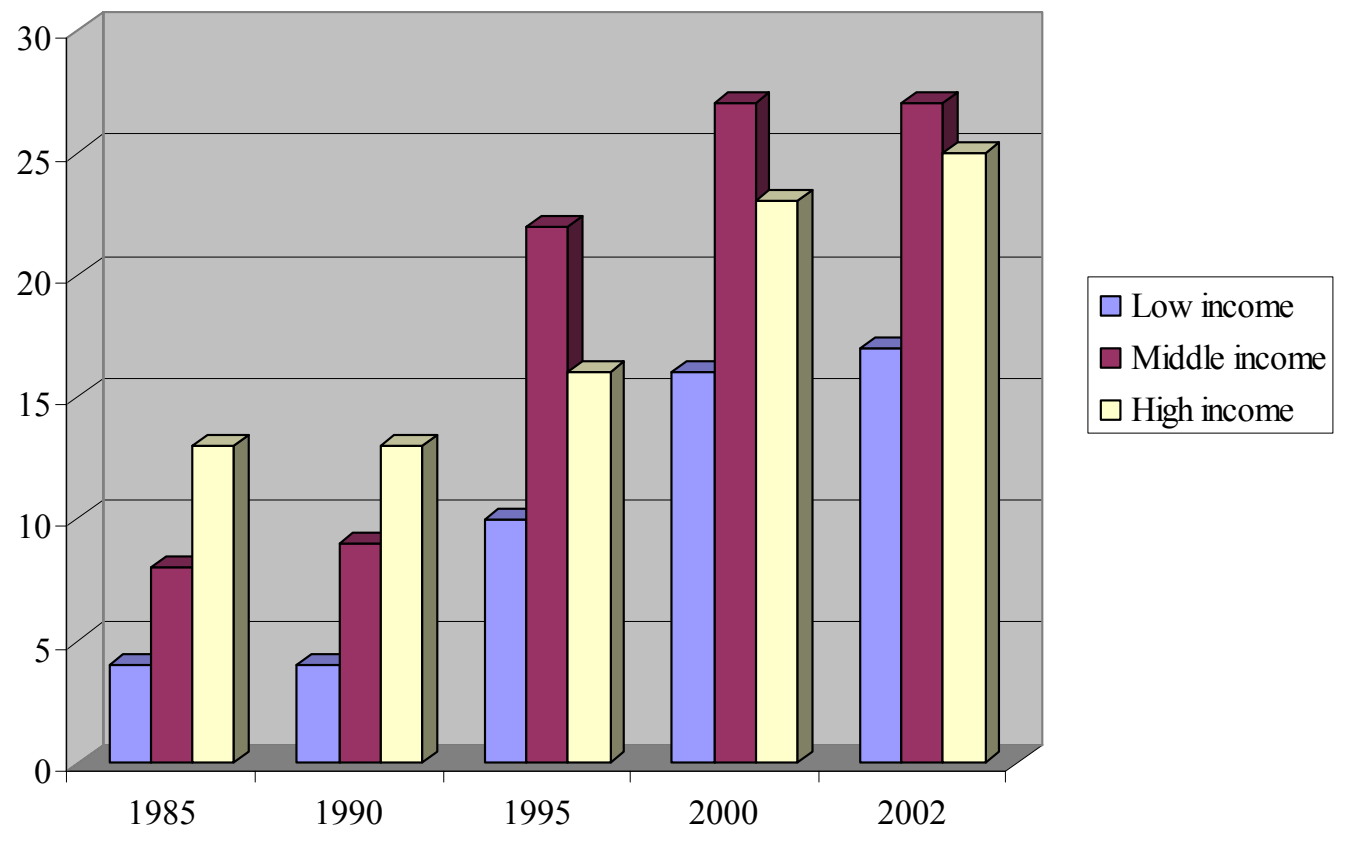

Source: WIPO.

How intensively is the Madrid system used by trademark holders? Calculating the share of Madrid registrations in total foreign registrations in countries which reported the figures on Madrid registration in a given year, we find that

\section{the share of Madrid registrations in total foreign registrations is similar across country groups.}

Madrid shares in 1998 averaged between 60 and 70 percent in the three country groups (Figure 4). The corresponding share was the highest (68 percent) in the low-income group, followed by middle-income countries and high-income economies (both 62 percent). Nonetheless, the main users of the Madrid system are likely to be residents from high-income countries which account for the largest share of foreign registration across all countries (recall Table 1). 
Figure 4: Madrid registrations as a share of total foreign registrations (Madrid members only), 1998

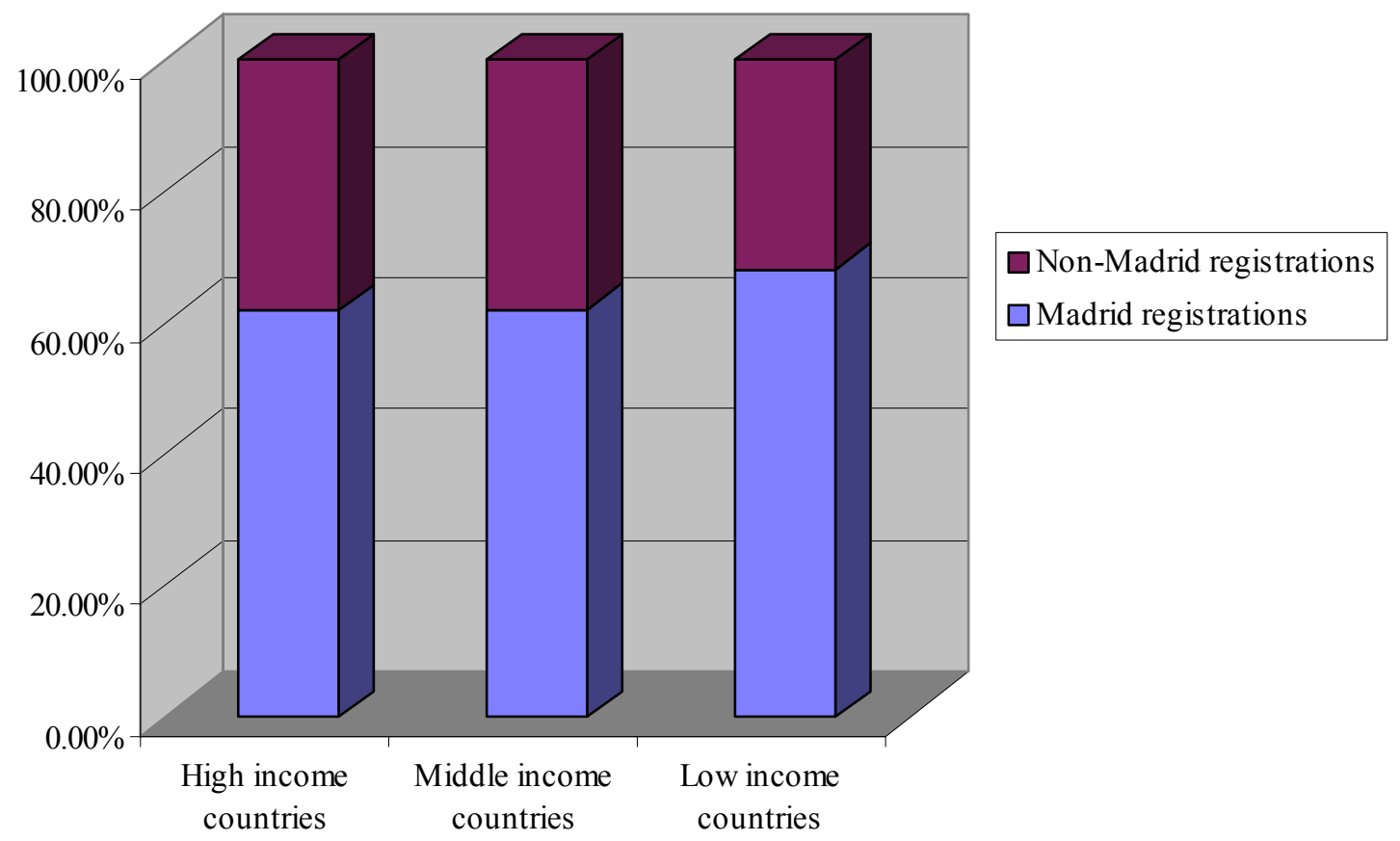

Notes: Calculations are based on 40 countries.

4. How valuable are trademarks across different income groups?

The economic value of trademarks differs significantly across firms, industries and countries. Understanding these differences would require a detailed micro-level analysis taking account of market-specific idiosyncrasies. Nonetheless, a crude indicator of the value of trademark registrations can be obtained by calculating the ratio of gross domestic product (GDP) to the number of registrations across income groups. In other words, this figure captures how many dollars of income fall on each registered trademark. We find that:

newly registered trademarks in high-income countries account for four to five times as much of GDP as in middle and low- income countries.

Figure 5 depicts the GDP-trademark ratios for the three income groups. In high-income countries, each registered trademark accounts for 32 million dollars of GDP, about four times as 
much as in middle-income countries ( 8 million dollars) and more than five times as much as in low-income countries (6 million dollars). ${ }^{14}$ Trademarks in high-income countries appear more "valuable," despite the fact that more trademarks per capita are registered in these countries. ${ }^{15}$

Figure 5: Ratio of GDP to number of trademark registrations, 1994-1998

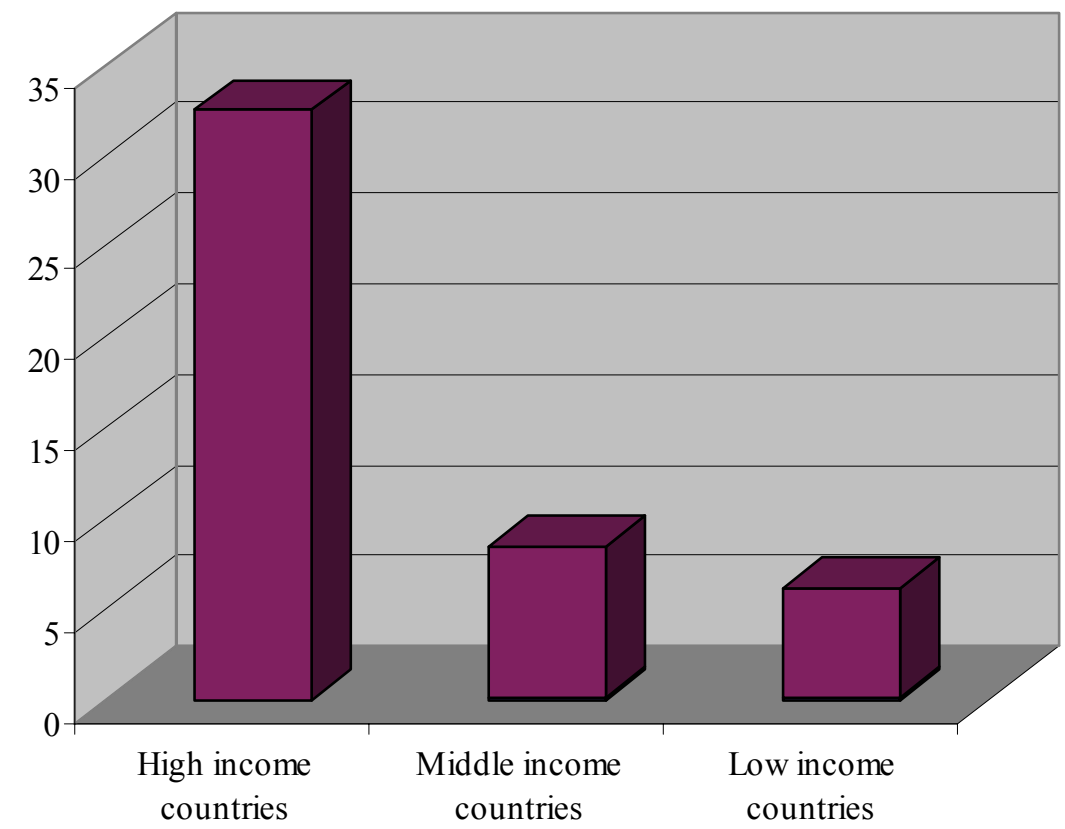

Notes: Ratios are calculated as the sum of all GDPs for a particular income group over the sum of all trademark registrations in this income group. The figures shown are simple averages over the period 1994-1998. The number of countries in the high-income group varies from 28 in 1994 to 24 in 1998; in the middle-income group the number fluctuates between 45 and 33 and for the low-income countries between 21 and 11 during the period covered.

While these comparisons across income groups provide interesting information, the calculated dollar figures should be seen only as a very crude indicator of the value of trademarks. New registrations may not correlate closely with the stock of trademarks in force in a given year, which is likely to account for most of firms' reputational assets in goods and service markets. In addition, the value of trademarks varies significantly across brands. Some estimates of the value of global brands have been made by Interbrand, a consultancy, based on the projected revenues which a brand is expected to generate. According to these calculations, the world's most

\footnotetext{
${ }^{14}$ GDP figures are expressed in constant 1995 US dollars.

${ }^{15}$ Calculating the ratio of newly registered trademarks to population across income groups, we find that there are 0.87 trademarks per 1,000 inhabitants in high-income countries, and 0.21 and 0.07 trademarks per 1,000 inhabitants in middle and low-income countries, respectively.
} 
valuable brand in 2001, Coca-Cola, was worth 69 billion dollars. It was followed by Microsoft with an estimated value of 64 billion dollars. The $100^{\text {th }}$ most valuable brand, Benetton, was worth one billion dollars. By contrast, trademarks registered by small enterprises that primarily seek to protect reputational assets in local markets are significantly less "valuable."

\section{Sectoral patterns}

The WIPO data also allow us to make comparisons between the number of trademark registrations in 33 manufacturing industries as well as agriculture (classified as one category) and 8 service sectors. ${ }^{16}$

As Figure 6 indicates, scientific equipment and pharmaceuticals are the most intense users of trademarks in the world, followed by paper, detergents and clothing and footwear.

\footnotetext{
${ }^{16}$ The sectoral distribution of trademarks is based on the international classes of the Nice Classification which is used in many, if not most, national and regional trademark systems and in the Madrid System .
} 
Figure 6: Sectoral distribution of trademark registrations, 1994-98

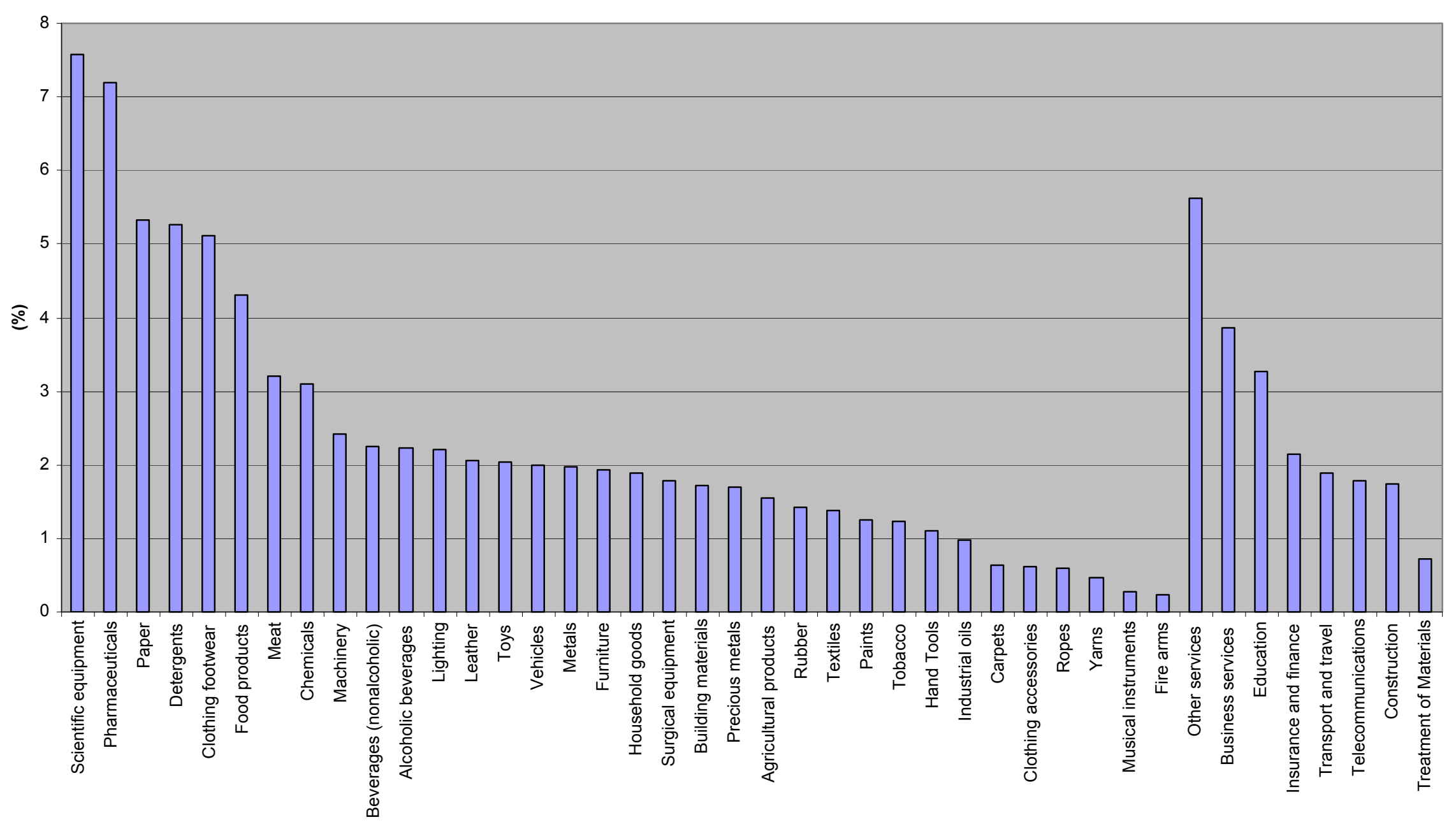


The data also indicate that:

there is a lot of similarity between the sectoral distribution of trademarks in countries belonging to different income groups.

The partial correlation between the importance of each sector in terms of its share in trademark registrations in middle and low-income countries is 0.98 . The corresponding figure for the high and middle-income group is 0.88 , while it takes a value of 0.84 for high and lowincome economies.

As Table 4 below demonstrates, in all three income groups the same nine sectors ranked among the top 10 categories in terms of their share in the total number of trademarks registered. These are such $R \& D$-intensive sectors as pharmaceuticals and scientific equipment and advertising-intensive industries such as clothing, footwear, detergents and food products. Note that the pharmaceutical sector accounts for the highest percentage of trademarks registered in middle and low-income countries (over 8 and 9 percent, respectively), while, among rich countries, scientific equipment tops the chart. In all three groups, service sectors (business services and "other" services) are also among the most intensive users of trademarks. ${ }^{17}$

Table 4: Sectors with the Highest Share of Trademark Registrations, 1994-98

\begin{tabular}{lcllll}
\hline \multirow{2}{*}{ High-income } & \multicolumn{7}{l}{ Sectoral share of trademark registrations } \\
Scientific equipment & \multicolumn{7}{l}{ Middle-income } & \multicolumn{2}{l}{ Low-income } \\
Paper & 9.3 & Pharmaceuticals & 8.1 & Pharmaceuticals & 9.2 \\
Other services & 6.5 & Scientific equipment & 6.2 & Detergents & 6.7 \\
Pharmaceuticals & 6.3 & Detergents & 5.7 & Scientific equipment & 6.6 \\
Clothing footwear & 5.7 & Other services & 5.1 & Other services & 5.1 \\
Business services & 5.7 & Clothing footwear & 4.7 & Food products & 4.7 \\
Detergents & 4.5 & Food products & 4.6 & Clothing footwear & 4.5 \\
Education & 4.5 & Paper & 4.5 & Paper & 4.2 \\
Food products & 4.3 & Chemicals & 3.6 & Chemicals & 3.4 \\
Meat & 3.9 & Business services & 3.5 & Business services & 3.1 \\
\hline
\end{tabular}

Notes: For purposes of comparison, calculated shares only refer to 12 high-income, 16 middle-income and 7 low-income countries, for which data in all 5 years are available.

There is also some similarity in terms of sectors dominated by trademarks registered by foreigners (see Table 5). In all country groups these are pharmaceuticals, chemicals and detergents. Not surprisingly these are the sectors, in which multinational corporations are

\footnotetext{
${ }^{17}$ The category "other" services encompasses such diverse sectors as restaurants, hospitality services, medical and beauty care, agricultural services, legal services and computer programming.
} 
very active. For instance, for thirteen of the hundred world's largest transnational corporations these are the main sectors of operation (UNCTAD 2001). ${ }^{18}$

\section{Table 5: Sectors with the Highest Ratio of Foreign to Domestic Trademark} Registrations, by Income Group, 1994-98

\begin{tabular}{llllll}
\hline High-income & \multicolumn{5}{l}{$\begin{array}{l}\text { Sectoral share of trademark registrations } \\
\text { Middle-income }\end{array}$} \\
\hline Surgical equipment & 3.56 & Pharmaceuticals & 5.40 & Pharmaceuticals & 36.61 \\
Pharmaceuticals & 3.02 & Chemicals & 4.91 & Detergents & 33.16 \\
Detergents & 2.85 & Detergents & 4.88 & Chemicals & 27.70 \\
Tobacco & 2.85 & Precious metals & 4.79 & Industrial oils & 24.66 \\
Chemicals & 2.56 & Scientific equipment & 4.50 & Rubber & 24.37 \\
Machinery & 2.46 & Machinery & 4.19 & Leather & 23.37 \\
Vehicles & 2.46 & Vehicles & 4.02 & Telecommunications & 23.01 \\
Rubber & 2.42 & Lighting & 3.98 & Yarns & 23.00 \\
Hand Tools & 2.42 & Leather & 3.79 & Carpets & 21.43 \\
Leather & 2.31 & Toys & 3.67 & Surgical equipment & 19.59 \\
& & & & & \\
\hline
\end{tabular}

Note: based on frozen sample described in the note to Table 4.

\section{Conclusions}

It is widely recognized that a firm's, industry's and country's export performance is greatly affected by its reputation in foreign markets, access to information on trading opportunities and other intangible assets. The importance of reputation for product quality and good business conduct takes on added significance for developing and least developed countries. Firms in these countries often lack a historical record or reliable trade performance and thus may be constrained in expanding into international markets. By contrast, firms whose reputation is already well-established abroad may find it easier to introduce new products into foreign markets and to gain additional customers. Data on trademark registrations offer interesting insights into how reputational assets are distributed and how they are exploited in international commerce.

The stylized facts presented in this paper indicate that there exists asymmetric ownership of trademarks. The majority of trademarks in the world, including those in developing countries, have been registered by firms from industrial countries. At the same

\footnotetext{
${ }^{18}$ Some countries report the same registered trademark in several sectoral categories. By comparing the total of sectoral trademark registrations to the aggregate total reported separately by national trademark offices, we were able to identify the countries where multiple counting of registrations occurs. We re-calculated the sectoral shares reported in this sections separately for countries that assign trademarks to only one sectoral category and for countries that allow for multiple designations. While sectoral shares and rankings differed somewhat from the ones reported for the total sample here, they were remarkably similar, suggesting that the potential bias from multiple counting is likely to be small.
} 
time, the global distribution of trademarks is not as uneven as the global distribution of invention patents. Primo Braga et al (2000), for example, report that in 1994-95 less than 5 percent of worldwide patents granted to residents only (approximating the first filing of patents) belonged to developing countries. ${ }^{19}$ This pattern may indicate that firms in developing countries are more likely to differentiate themselves by investing in brands rather than new technologies. It also suggests that a larger number of firms in developing countries may benefit from stronger enforcement of trademarks rather than from stronger enforcement of patents. ${ }^{20}$

In the case of patents, economists have traditionally associated asymmetric intellectual property ownership with rent transfers from the developing to the developed world (see MacCalman, 2001). It is less clear to what extent asymmetric trademark ownership may be the source of similar rent transfers. Trademarks, unlike patents, do not necessarily confer market power to the intellectual property-holding firm and can, in principle, co-exist with a competitive market structure. However, when consumers are imperfectly informed or attach a status value to products, competition may be imperfect (see Fink and Smarzynska, 2002) and trademark owners may generate rents. More research is needed to assess the extent of crossborder rent transfers associated with trademarks. Both the stylized facts and the dataset presented in this paper could serve as a starting point for further empirical analysis.

\footnotetext{
${ }^{19}$ For industrial designs — another form of registered intellectual property - the global distribution is even more asymmetrical. Less than 1 percent of domestic grants originated in the developing world.

${ }^{20}$ Anecdotal evidence on the use of the intellectual property system by Chinese firms confirms this point. See Maskus et al (forthcoming).
} 


\section{References}

Fink, Carsten and Beata Smarzynska. (2002). "Trademarks, Geographical Indications and Developing Countries" in Development, Trade and the WTO: A Handbook, Bernard Hoekman, Aaditya Mattoo and Philip English, eds. The World Bank, Washington DC.

Fink, Carsten, Beata Smarzynska Javorcik and Mariana Spatareanu. (2003). "Income-Related Biases in International Trade: What Do Trademark Registration Data Tell Us?” World Bank Policy Research Working Paper 3150. The World Bank, Washington DC.

Landes, William M. and Richard A. Posner. (1987), "Trademark Law: An Economic Perspective," Journal of Law and Economics, Vol. 30(2), pp. 265-309.

Maskus, Keith, Sean M. Dougherty, and Andrew Mertha. (forthcoming). "Intellectual Property Rights and Economic Development in China." In Carsten Fink and Keith E. Maskus (eds). Empirical Investigations on the Effects of Intellectual Property Protection on Market Structure, Trade and Foreign Direct Investment. (Oxford University Press).

McCalman, Philip. (2001). "Reaping What You Sow: An Empirical Analysis of International Patent Harmonization.” Journal of International Economics, Vol.55(1), pp. 161-86.

Primo Braga, Carlos A., Carsten Fink and Claudia Paz Sepulveda. (2000). "Intellectual Property Rights and Economic Development.” World Bank Discussion Paper No. 412. (Washington, DC: The World Bank).

UNCTAD. (2001). World Investment Report. Promoting Linkages.

Watal, Jayashree. (2001). "Intellectual Property Rights in the WTO and Developing Countries.” (Oxford University Press). 


\section{Annex I: Overview of the databases}

Based on the data provided by the World Intellectual Property organization (WIPO), we created the following databases: (i) Summary database containing the total number of registrations by country; (ii) Bilateral database including information on the number of registrations broken down by country of origin of the trademark holder; (iii) Sectoral database presenting information on the number of registrations broken down by sector and country of origin of the trademark holder. The rationale for maintaining separate databases is that national intellectual property offices report these data separately to WIPO and country coverage as well as reporting methodologies differ for the three data sources.

\section{Summary database}

This database presents information on the number of trademarks registered in reporting countries (also referred to as destination countries) each year during the period 1994-98. It contains separate figures on the number of trademarks registered by residents and nonresidents. It also provides the indication under which system registrations have been made (national offices, Madrid System and Banjul Protocol). ${ }^{21}$

The database is composed of 435 observations, composed of 116 reporting countries plus the Office for Harmonization in the Internal Market (OHIM) and the African Intellectual Property Organization (OAPI). Almost half of the observations (203) pertain to middle-income economies, one third (144) refer to high-income countries and slightly more than one-fifths (88) to low-income destinations.

The total number of countries in the sample varies over the five years, from the highest 95 for 1994 and 1995 to the lowest 74 for 1998 (see Table A1). In terms of income groups, we observe a decrease in the number of middle and low-income countries over time.

\begin{tabular}{||ccccc||}
\hline \multicolumn{5}{|c||}{ Table A1: Sample Composition in the } \\
Summary Database \\
\hline \hline \multicolumn{5}{|c||}{ Destination countries } \\
\hline \hline \multirow{5}{*}{ Year } & High & Middle & Low & All \\
& Income & Income & Income & countries \\
\hline 1994 & 31 & 42 & 22 & 95 \\
1995 & 28 & 46 & 21 & 95 \\
1996 & 29 & 46 & 21 & 96 \\
1997 & 28 & 36 & 11 & 75 \\
1998 & 28 & 33 & 13 & 74 \\
Total & 144 & 203 & 88 & 435 \\
\hline
\end{tabular}

The complete list of countries included in the summary database can be found in Table A2.

\footnotetext{
${ }^{21}$ Within the framework provided by the African Regional Industrial Property Organization (ARIPO), the Banjul Protocol on Marks sets up a single trademark filing system for Member States' registrations of trademarks. Adopted by the ARIPO Administrative Council in 1993, the Banjul Protocol entered into force on March 6, 1997, for Malawi, Swaziland and Zimbabwe. Lesotho and Tanzania acceded in 1999. According to the Protocol, the applicant has the choice to either apply through the National Office of one of the contracting states or directly with the ARIPO Office, and designate the states where he seeks protection for his mark. For a detailed description of the role and institutions of the Banjul Protocol see http://www.aripo.wipo.net.
} 
Table A2: Complete list of countries in the summary database

\begin{tabular}{ll}
\hline Income groups* & Countries \\
\hline High Income & Andorra, Australia, Austria, Barbados, Benelux, Brunei Darussalam, Canada, \\
& Denmark, Finland, France, Germany, Greece, Hong Kong, Iceland, Ireland, \\
Israel, Italy, Japan, Liechtenstein, Macau, Malta, Monaco, Netherlands & Antilles, New Zealand, Norway, Office for the Harmonization of the Internal \\
& Market (OHIM), Oman, Portugal, Slovenia, Spain, Sweden, Switzerland, \\
& United Kingdom, United States of America. \\
& \\
Algeria, Argentina, Belarus, Bolivia, Brazil, Bulgaria, Chile, China, Colombia, \\
Croatia, Cuba, Czech Republic, Dominica, Ecuador, El Salvador, Estonia, \\
Georgia, Guatemala, Honduras, Hungary, Iran (Islamic Republic of), Jamaica, \\
Jordan, Kazakhstan, Latvia, Lithuania, Malaysia, Mauritius, Mexico, Morocco, \\
Panama, Papua New Guinea, Peru, Philippines, Poland, Republic of Korea, \\
Romania, Russian Federation, Saint Lucia, Samoa, Seychelles, Slovakia, South \\
Africa, Sri Lanka, Suriname, TFYR Macedonia, Thailand, Trinidad \& Tobago, \\
Tunisia, Turkey, Turkmenistan, Uruguay, Venezuela, Yugoslavia. \\
\\
Armenia, Azerbaijan, Bangladesh, Burundi, Cambodia, Ethiopia, Ghana, Haiti, \\
India, Indonesia, Kenya, Kyrgyzstan, Laos, Madagascar, Malawi, Mongolia, \\
Nepal, Nicaragua, African Intellectual Property Organization (OAPI), \\
Pakistan, Republic of Moldova, Rwanda, Sierra Leone, Tajikistan, Ukraine, \\
Uzbekistan, Viet Nam, Zaire, Zambia, Zimbabwe
\end{tabular}

* The World Bank country classification has been used in assigning countries to different income groups.

As mentioned, in addition to 116 individual countries, the database contains information on registrations through the OAPI and the OHIM offices. The OAPI (African Intellectual Property Organization, or Organisation pour la proprieté intellectuelle, following the French version of the acronym) was established by the Libreville Agreement of September 1962 and the Bangui Agreement of 1977 (revised in 1999). It is headquartered in Yaoundé (Cameroon) and registers and issues titles, in the name and on account of the African states of Benin, Burkina Faso, Cameroon, Central African Republic, Chad, Congo, Côte d'Ivoire, Gabon, Guinea, Guinea Bissau, Mali, Mauritania, Niger, Senegal, and Togo. Therefore, OAPI residents are defined as persons or companies residing in or having established business presence on the territory of one of the member states, and OAPI non-residents are persons or companies residing in or operating on the territory of other countries. ${ }^{22}$

The OHIM (Office for Harmonization in the Internal Market) has its seat in Alicante (Spain) and was set up by a Regulation of the Council of the European Union of 20 December 1993. Its task is to register Community trademarks, which are legally enforceable and uniformly protected throughout the territory of the European Union. Registrations made via the Office are valid for a period of 10 years and may be transferred or allowed to lapse, or renewed indefinitely. ${ }^{23}$

In constructing the 'summary' database, we encountered a variety of problems due to missing data entries:

- Several countries only reported data on applications, but not registrations.

\footnotetext{
${ }^{22}$ See the OAPI website, hosted by WIPO at http://www.oapi.wipo.net.

${ }^{23}$ For a more detailed description of the OHIM and the Community trademark, see http://oami.eu.int.
} 
- Some countries only reported total data, with missing disaggregation between foreign and domestic registrations and/or missing data on international registrations through the Madrid or Banjul protocol. ${ }^{24}$

The affected observations have accordingly been flagged in the database (see Annex II). In calculating the descriptive statistics presented in this paper, we only relied on observations that did not suffer from these kinds of data problems (and these are the observations summarized in Table A1).

\section{Bilateral database}

This database contains information on trademark registrations disaggregated by country of registration and the country of the party requesting a registration (also referred to as the source country). As the summary database, it also provides the indication under which system registrations have been made (national office, Madrid System and Banjul Protocol).

The 'bilateral' database contains 115 destinations (including the OAPI and the OHIM offices), that are made up of the destinations listed in table 19 for the summary database minus Indonesia, France and Philippines.

A breakdown of observations by income group of the destination country is provided in Table A3 below. Middle-income destinations (46.8 percent) are dominant, followed by highincome countries (33.6 percent). Low-income destinations constitute 20 percent of all observations. Note that the net changes presented in the table conceal movements in and out of the sample. For instance, the net addition of three middle-income countries between 1994 and 1995 is a result of the entry by Dominica, Honduras, Malaysia, St. Lucia, Samoa and Seychelles and the exit of Bolivia, Poland and Thailand.

\begin{tabular}{||ccccc||}
\hline \multicolumn{5}{||c||}{ Table A3: Sample Composition in the Bilateral } \\
Database \\
\hline \hline \multicolumn{5}{|c||}{ Destination Countries } \\
\hline \hline Year & High & Middle & Low & All \\
& Income & Income & Income & countries \\
1994 & 29 & 41 & 21 & 91 \\
1995 & 26 & 44 & 21 & 91 \\
1996 & 29 & 43 & 20 & 92 \\
1997 & 28 & 34 & 11 & 73 \\
1998 & 28 & 31 & 11 & 70 \\
Total & 140 & 193 & 84 & 417 \\
\hline \hline
\end{tabular}

The bilateral database includes thirty-nine designated source countries, a residual category "other source countries" and a category for "domestic" registrations (see Table A4). Among the thirty-nine listed source countries, there are 24 high-income economies, 14 middle-income countries and one low-income economy (India).

\footnotetext{
${ }^{24}$ In deciding whether data on international Madrid or Banjul registrations are truly missing, we, of course, took account of Madrid and Banjul membership of the destination country in question.
} 


\section{Table A4: Source Countries in the Bilateral Database}

\begin{tabular}{ll}
\hline Income groups & Countries \\
\hline High income & $\begin{array}{l}\text { Australia, Austria, Belgium, Canada, Denmark, Finland, France, } \\
\text { Germany, Greece, Ireland, Israel, Italy, Japan, Liechtenstein, } \\
\text { Luxembourg, Netherlands, New Zealand, Norway, Portugal, Spain, } \\
\text { Sweden, Switzerland,United Kingdom, United States of America }\end{array}$ \\
Middle income & $\begin{array}{l}\text { Argentina, Brazil, Bulgaria, China, Czech Republic, Hungary, Mexico, } \\
\text { Poland, Republic of Korea, Romania, Russian Federation, Slovakia, } \\
\text { South Africa, Turkey }\end{array}$ \\
Low income & India \\
\hline
\end{tabular}

We encountered similar missing data problems as the ones described for the 'summary' database. Again, in calculating the descriptive statistics presented in this paper, we only relied on observations that did not suffer from these problems (and these are the observations summarized in Table A3).

\section{Sectoral database}

This dataset contains information on trademark registrations and applications disaggregated by country of registration (also referred to as destination), the country of the party requesting a registration (also referred to as source), as well as the sectoral class of registration. As for the previous two databases, the sectoral database provides the indication under which system registrations and applications (or designations, when appropriate) have been made (national office, Madrid System and Banjul Protocol).

The complete set of destination countries included in the sectoral database can be found in Table A5. 
Table A5: Destination countries in the sectoral database

\begin{tabular}{ll}
\hline Income groups & Countries \\
\hline High Income & Andorra, Australia, Austria, Benelux, Brunei Darussalam, Denmark, Finland, \\
& France, Germany, Hong Kong, Iceland, Ireland, Italy, Japan, Liechtenstein, \\
& Macau, Malta, Monaco, Netherlands Antilles, New Zealand, Norway, Office \\
for the Harmonization of the Internal Market (OHIM), Oman, Portugal, San & \\
& Marino, Slovenia, Spain, Sweden, Switzerland, United Kingdom. \\
Middle income & Albania, Algeria, Belarus, Bolivia, Bosnia \& Herzegovina, Brazil, Bulgaria, \\
& Chile, China, Colombia, Croatia, Cuba, Czech Republic, Dem. People's \\
& Republic of Korea, Ecuador, Egypt, El Salvador, Estonia, Georgia, Guatemala, \\
& Honduras, Hungary, Iran (Islamic Republic of), Jamaica, Kazakhstan, Latvia, \\
& Lithuania, Mexico, Morocco, Panama, Peru, Poland, Romania, Russian \\
& Federation, Slovakia, South Africa, Sri Lanka, TFYR Macedonia, Thailand, \\
& Trinidad \& Tobago, Tunisia, Turkey, Uruguay, Venezuela, Yugoslavia. \\
& African Regional Industrial Property Organization [ARIPO], Armenia, \\
& Azerbaijan, Ghana, Haiti, India, Indonesia, Kenya, Kyrgyzstan, Laos, Lesotho, \\
& Liberia, Malawi, Mongolia, Mozambique, Nicaragua, African Intellectual \\
& Property Organization (OAPI), Pakistan, Republic of Moldova, Sierra Leone, \\
& Sudan, Swaziland, Tajikistan, Ukraine, Uzbekistan, Viet Nam, Zimbabwe. \\
\hline
\end{tabular}

The sectoral database has 358,560 observations, encompassing 104 destination countries and 22 source countries (plus one entry for domestic and one entry for "others countries"). ${ }^{25}$ Table A6 lists the number of countries per income group and for each year. The majority of destinations is made up of middle-income countries (46.59\%), followed by high-income countries $(30.25 \%)$ and low-income countries $(23.16 \%)$.

\begin{tabular}{||ccccc||}
\hline \hline \multicolumn{5}{|c||}{ Table A6: Sample Composition in the } \\
Sectoral Database \\
\hline \hline \multicolumn{5}{|c||}{ Destination countries } \\
\hline \hline \multirow{5}{*}{ Year } & High & Middle & Low & All \\
& Income & Income & Income & countries \\
\hline 1994 & 18 & 35 & 14 & 67 \\
1995 & 19 & 37 & 14 & 70 \\
1996 & 25 & 40 & 18 & 83 \\
1997 & 25 & 32 & 17 & 74 \\
1998 & 24 & 27 & 22 & 73 \\
Total & 111 & 171 & 85 & 367 \\
\hline \hline
\end{tabular}

Table A7 shows the composition of country sources by income group (excluding the two entries for domestic registrations and the "Other countries" category).

\footnotetext{
${ }^{25}$ Reference is made here to the version of the sectoral database that only includes observations, where we did not encounter any data problems or inconsistencies (see below and Annex II).
} 
Table A7: Source Countries in the Sectoral Database

\begin{tabular}{ll}
\hline Income groups & Countries \\
\hline High income & $\begin{array}{l}\text { Australia, Austria, Belgium, Canada, Denmark, Finland, France, } \\
\text { Germany, Italy, Japan, Netherlands, Norway, Portugal, Spain, Sweden, } \\
\text { Switzerland, United Kingdom, United States of America }\end{array}$ \\
Middle income & China, Hungary, Republic of Korea, Russian Federation \\
\hline
\end{tabular}

The sectoral database disaggregates data on national, international and Banjul-related registrations and applications over 42 sectors, according to the trademark-specific Nice classification. Table A8 below reports the list of goods industries (classes 1 to 34) and services sectors (classes 35 to 42 ) identified in the Nice classification.

As in the case of the previous two databases, we encountered missing data and certain data inconsistencies:

- The original spreadsheets provided by WIPO contained sectoral totals, i.e. the sum of applications or registrations over all source countries in a given trademark class. In certain cases, the reported totals differed from the totals calculated based on the individual source entries (in most of these cases individual entries were missing altogether).

- Some countries only reported total data, with missing disaggregation between foreign and domestic registrations and/or missing data on international registrations through the Madrid or Banjul protocol. ${ }^{26}$

- We calculated the sum of registrations over all foreign sources and sectoral groups and compared the resulting figures to the ones reported in the summary database. In a number of cases the match was perfect or very close. For a considerable number of countries, however, the calculated totals exceeded the ones reported in the summary database. This can be explained by multiple counting in the sectoral database: some national offices allow multiple registrations of one trademark in more than one sectoral class. However, in a few cases, the calculated totals fell short of the ones reported in the summary database, which we flagged as problem cases.

In calculating the descriptive sectoral statistics presented in this paper, we only relied on observations that did not suffer from missing data or data inconsistencies. Moreover, we tested whether multiple counting of sectoral registrations biases the results discussed in the text. Specifically, we re-calculated the sectoral statistics using the sub-sample of observations where the number of registrations exceeded the ones in the summary database. While sectoral shares and rankings differed somewhat from the ones reported for the total sample in the text, they were remarkably similar, suggesting that the potential bias from multiple counting is likely to be small.

\footnotetext{
${ }^{26}$ In deciding whether data on international Madrid or Banjul registrations are truly missing, we, of course, took account of Madrid and Banjul membership of the destination country in question.
} 
Table A8: Classes of goods and services in the sectoral database, Nice classification

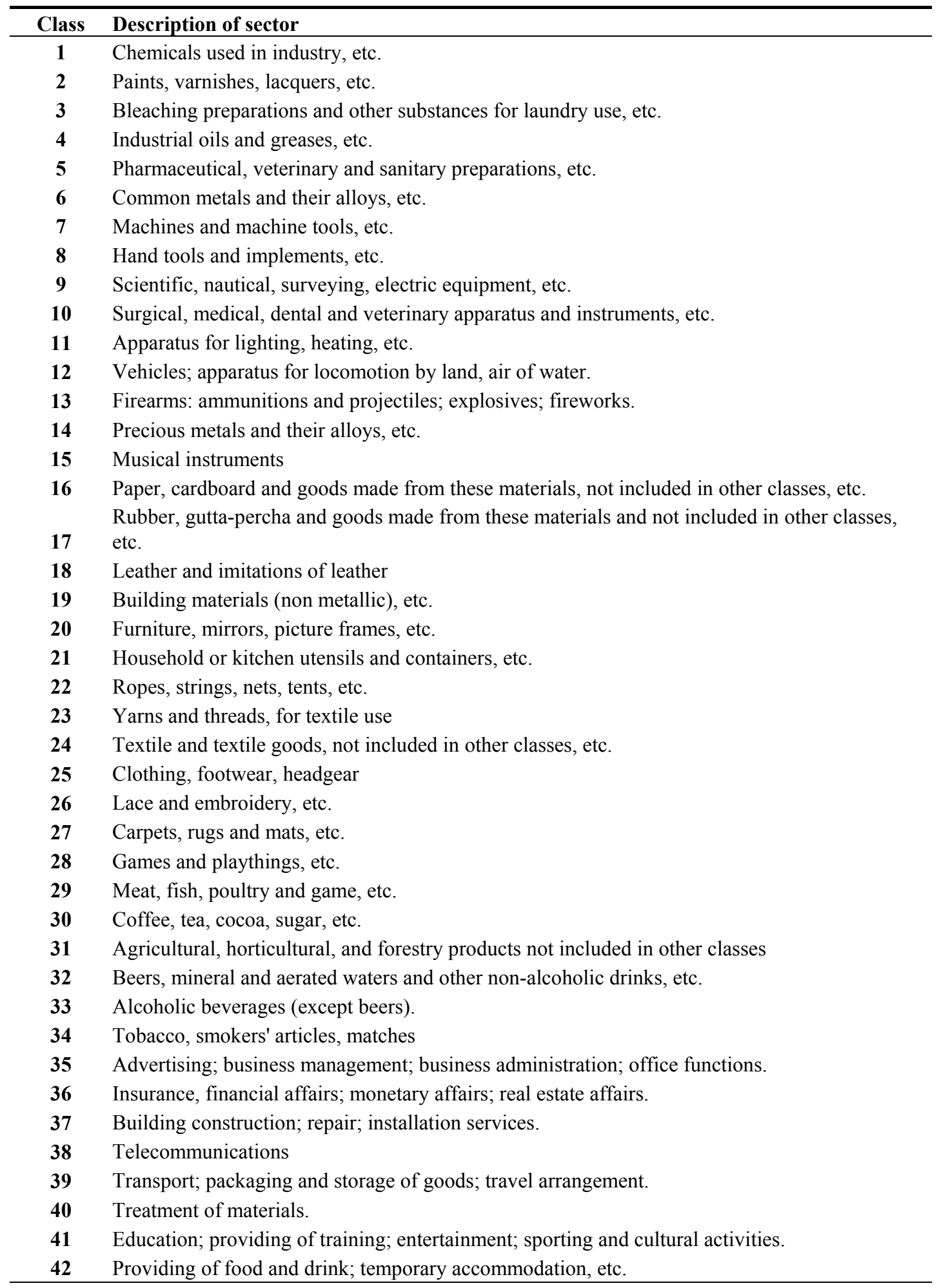

Source: WIPO. 


\section{Annex II: Description of variables included in the databases}

The dataset presented in this annex is wider in scope than the data described in Annex I and used to produce the results discussed in the paper, as its covers the complete information obtained from WIPO and includes observations which exhibited some inconsistencies in the original data source. As explained below, the inconsistent observations in the three databases have been marked by means of various flag variables introduced by the authors.

\section{Summary database}

The summary database is composed of 21 variables:

1-dest: destination country (labeled as "Reporting Country" in the original WIPO files).

2-year: year in which the application or registration has taken place.

\section{3-destd :}

H: labels all the destination countries falling into the high-income group

M: labels all the destination countries falling into the middle-income group

L: labels all the destination countries falling into the low-income group

4- ressns: number of trademarks registrations in services made by residents of the reporting country (from now on referred to as "destination state") and received by its national trademarks office ("the Office concerned"). The disaggregation between goods and services for the summary database (data coded either ressns or restng) is available only for years 1994 and 1995.

5-nressns: number of trademarks registrations in services made by non residents of the destination state and received by its national trademarks office ("the Office concerned"). The disaggregation between goods and services for the summary database (data coded either nressns or nrestng) is available only for years 1994 and 1995.

6-restng: number of trademarks registrations in goods made by residents of the destination state and received by its national trademark office ("the Office concerned"). The disaggregation between goods and services for the summary database (data coded either ressns or restng) is available only for years 1994 and 1995.

7-nrestng: number of trademarks registrations in goods made by non residents of the destination state and received by its national trademarks office ("the Office concerned"). The disaggregation between goods and services for the summary database (data coded either nressns or nrestng) is available only for years 1994 and 1995.

8- nressms: number of trademarks designations in services made by non residents of the destination state under either the Madrid Agreement or the Madrid Protocol, and "which have not been the subject of a refusal of protection or which are no longer open to such refusal". The disaggregation between goods and services for the summary database (data coded either nressms or nrestmg) is available only for years 1994 and 1995

[9- ressms: number of trademarks designations in services made by residents of the destination state under either the Madrid Agreement or the Madrid Protocol, and "which have 
not been the subject of a refusal of protection or which are no longer open to such refusal". ]$^{* * *}$

10- nrestmg: number of trademarks designations in goods made by non residents of the destination state under either the Madrid Agreement or the Madrid Protocol, and "which have not been the subject of a refusal of protection or which are no longer open to such refusal". The disaggregation between goods and services for the summary and bilateral databases (data coded either nressms or nrestmg) is available only for years 1994 and 1995

[11- restmg: number of trademarks designations in goods made by residents of the destination state under either the Madrid Agreement or the Madrid Protocol, and "which have not been the subject of a refusal of protection or which are no longer open to such refusal".] ${ }^{* * *}$

12-restn: number of trademarks registrations made by residents of the destination state and received by its national trademarks office ("the Office concerned"). For years 1994 and 1995, restn reports the sum of restng and ressns. For years 1996, 1997 and 1998, restn reports the data coded under "TN" registrations (goods+services) in the original WIPO files.

13-nrestn: number of trademarks registrations made by non residents of the destination state and received by its national trademarks office ("the Office concerned"). For years 1994 and 1995, nrestn reports the sum of nrestng and nressns. For years 1996, 1997 and 1998, nrestn reports the data coded under "TN" registrations (goods+services) in the original WIPO files.

14-nrestm: number of trademarks designations under either the Madrid Agreement or the Madrid Protocol, and "which have not been the subject of a refusal of protection or which are no longer open to such refusal". For years 1994 and 1995, nrestm reports the sum of nrestmg and nressms. For years 1996, 1997 and 1998, nrestm reports the data coded under "TM" registrations (goods+services) in the original WIPO files.

[15- restm: number of trademarks designations under either the Madrid Agreement or the Madrid Protocol, and "which have not been the subject of a refusal of protection or which are no longer open to such refusal".]***

16-rests: number of trademarks registrations under the Banjul Protocol of the African Regional Industrial Property Organization (ARIPO) made by residents of ARIPO member states

17-nrests: number of trademarks registrations under the Banjul Protocol of the African Regional Industrial Property Organization (ARIPO) made by non residents of ARIPO member states.

17- totsns: total number of trademarks registrations for services received by national trademarks offices ("the Office concerned"). This aggregated information was only available for the case of Venezuela in year 1994.

19- tottng: total number of trademarks registrations for goods received by national trademarks offices ("the Office concerned"). This aggregated information was only available for the three destination countries of Argentina and Venezuela, in year 1994, and for Syria in year 1995. 
20- tot: total number of trademarks registrations received by national trademarks offices ("the Office concerned"). This aggregated information was only available for the case of Argentina in year 1994.

21- flag: see below in the section devoted to the description of the Summary-Bilateral database

***Note: all the observations for the variables in square brackets are either equal to zero or missing, since no domestic registration is allowed under the Madrid System (e.g. residents of member countries have to go through their national trademarks office when registering for a mark in their state). However, since the entry was present in the original WIPO files for Madrid member countries, we have reported it into our database as well.

\section{Bilateral database}

The database is obtained from merging the summary and bilateral (foreign registrations disaggregated by source countries) dataset. It contains the following variables:

1-dest: destination country (labeled as "Reporting Country" in the original WIPO files).

2-year: in which the application or registration has taken place.

3-source: source country (labeled as "Country of residence of the applicant" in the original WIPO files). In addition to the country names, there are also the codes "XX", to designate domestic registrations, and "Others", to designate registrations made by countries other than the ones included in the individual sources.

4- sns: number of trademarks registrations in services received by national trademarks offices ("the Office concerned"). The disaggregation between goods and services for the summary and bilateral databases (data coded either sns or tng) is available only for years 1994 and 1995.

5- tng: number of trademarks registrations in goods received by national trademarks offices ("the Office concerned"). The disaggregation between goods and services for the summary and bilateral databases (data coded either sns or tng) is available only for years 1994 and 1995.

6-sms: number of trademarks designations in services under either the Madrid Agreement or the Madrid Protocol, and "which have not been the subject of a refusal of protection or which are no longer open to such refusal". The disaggregation between goods and services for the summary and bilateral databases (data coded either sms or tmg) is available only for years 1994 and 1995.

7-tmg: number of trademarks designations in goods under either the Madrid Agreement or the Madrid Protocol, and "which have not been the subject of a refusal of protection or which are no longer open to such refusal". The disaggregation between goods and services for the summary and bilateral databases (data coded either sms or tmg) is available only for years 1994 and 1995. 
8-tn: number of trademarks registrations received by national trademarks offices ("the Office concerned"). For years 1994 and 1995, tn reports the sum of tng and sns. For years 1996, 1997 and 1998, th reports the data coded under "TM" registrations (goods+services) in the original WIPO files.

9-tm: number of trademarks designations under either the Madrid Agreement or the Madrid Protocol, and "which have not been the subject of a refusal of protection or which are no longer open to such refusal". For years 1994 and 1995, tm reports the sum of tmg and sms. For years 1996, 1997 and 1998, rtm reports the data coded under "TM" registrations (goods+services) in the original WIPO files.

10-ts: number of trademarks registrations under the Banjul Protocol of the African Regional Industrial Property Organization (ARIPO)

\section{1- destd :}

H: labels all the destination countries falling into the high-income group

M: labels all the destination countries falling into the middle-income group

L: labels all the destination countries falling into the low-income group

\section{2- sourced:}

H: labels all the source countries falling into the high-income group

M: labels all the source countries falling into the middle-income group

L: labels all the source countries falling into the low-income group (India)

O: labels all the source countries not falling into any of the other categories

Dom: labels the observations where there the destination country is also source

\section{3- "Flag" variable}

OK: classifies the observations for which we have complete data in both the summary and the bilateral database.

ALL: codes those observations for which data are missing on all marks registrations in the summary database and for which no entry appears in the bilateral database.

M2Res: classifies the observations for which data about residents are missing in the summary database.

M2Tn: indicates the observations that have missing entries for all (residents and non residents) national registrations in the summary database.

M3M2NresTn: labels those observations for which data is not reported on registrations made by non residents through the country office in both the summary and bilateral databases.

M3B: codifies the observations for which both national and Madrid registrations disaggregated by source countries appear as missings (=blanks) in the bilateral database (and for which only the totals are reported).

M3Tm: labels those observations that have missing entries for data on Madrid registrations in the bilateral database. 
M3Tn: indicates observations for which data on goods' registrations for years 1994 and 1995 made through the national offices is missing in the bilateral database.

M3Sn: codifies the observations that have missing entries for data on services registrations in the bilateral database (for 1994 and 1995 only).

\section{Sectoral database}

The original sectoral database is composed of 14 variables:

1-dest: destination country (labeled as "Reporting Country" in the original WIPO files).

2-year: in which the application or registration has taken place.

3-class: class of good/service in which the application or registration has taken place. Classes range from 1 to 42 . According to the Nice Classification, classes 1 to 34 pertain to goods, whereas classes 35 to 42 are relative to services.

4-source: source country (labeled as "Country of residence of the applicant" in the original WIPO files). In addition to the country names, there are also the codes "XX", to designate domestic registrations, "Others", to designate registrations made by countries other than the ones included in the individual sources, and "Total", which is the reported total (sum of all the single source entries, present only in the raw sectoral dataset).

5- atn: number of trademarks applications filed directly with the national trademarks offices ("the Office concerned"). For years 1994 and 1995, atn refers only to goods. For years 1996, 1997 and 1998, it refers to both goods and services.

6- rtn: number of trademarks registrations received by national trademarks offices ("the Office concerned”). For years 1994 and 1995, rtn refers only to goods. For years 1996, 1997 and 1998, it refers to both goods and services.

7- atm: number of trademarks designations (whether in the international application or subsequently) under the Madrid Agreement or Protocol. For years 1994 and 1995, atm refers only to goods. For years 1996, 1997 and 1998, it refers to both goods and services.

8- rtm: number of trademarks designations under either the Madrid Agreement or the Madrid Protocol, and "which have not been the subject of a refusal of protection or which are no longer open to such refusal". For years 1994 and 1995, rtn refers only to goods. For years 1996, 1997 and 1998, it refers to both goods and services.

9- ats: number of trademarks designations in applications for registrations filed under the Banjul Protocol of the African Regional Industrial Property Organization (ARIPO).

10- rts: number of trademarks registrations processed under the Banjul Protocol of the African Regional Industrial Property Organization (ARIPO). 
11-asn: number of trademarks applications filed directly with the national trademarks offices ("the Office concerned") for services, in years 1994 and 1995.

12- rsn : number of trademarks registrations received by national trademarks offices ("the Office concerned") for services, in years 1994 and 1995.

13-asm: number of trademarks designations (whether in the international application or subsequently) under the Madrid Agreement or Protocol, for services in years 1995 and 1995.

14-rsm: number of trademarks designations under either the Madrid Agreement or the Madrid Protocol, and "which have not been the subject of a refusal of protection or which are no longer open to such refusal", for services in years 1994 and 1995.

In order to calculate trademarks flows between countries' income groups, we have then classified destinations and sources by income group, following the World Bank criteria. The constructed variables resulting from this categorization, are

\section{destd :}

H: labels all the destination countries falling into the high-income group

M: labels all the destination countries falling into the middle-income group

L: labels all the destination countries falling into the low-income group

sourced:

H: labels all the source countries falling into the high-income group

M: labels all the source countries falling into the middle-income group

O: $\quad$ labels all the source countries not falling into any of the other categories

Dom: labels the observations where there the destination country is also source

Tot: labels the reported totals (this variable is present only in the raw sectoral dataset).

We have then codified the observations of this sectoral database according to a set of other different flagging criteria.

FlagSectReg: describes the consistency between reported totals and calculated totals within the sectoral database.

We have performed a first type of consistency check on the matching between class totals as reported in the original sectoral WIPO files and class totals as calculated by adding the number of registrations as reported for each entry source. Out of our sample, containing 372 504 observations, 358560 were flagged "OK", to indicate the cases where this first consistency check had produced positive results (e.g. reported totals matching calculated totals). For the cases of mismatching, we have codified the observations as follows: 
M1tn: indicates those observations where single -by source entries are missing for registrations made through the national office but there is a positive reported total.

M1tntm: indicates those observations where single -by source entries are missing both for registrations made through the national office and registrations made under the Madrid System but there are two positive reported totals

M1tntm Tottn: identifies those observations where single -by source entries are missing both for registrations made through the national office and registrations made under the Madrid System and there is only a positive total for the Madrid registrations, while the total for the registrations made through the national offices is also missing

WIPO !: classifies the cases where reported totals are positive and different from the positive (calculated) sum of single -by source entries (possibly a mistake made by WIPO). This labeling only applies to the case of Yugoslavia for services in classes 41 and 42 for year 1994.

A check of consistency between the original WIPO files and the new database file has also been performed, using the totals provided in the summary database.

The variable typeofobs incorporates the results of this check:

-F: describes those observations for which there are fewer registrations in the sectoral database than in the summary dataset.

-L: labels the observations for which registrations in the sectoral database outnumber registrations in the summary database

-N: codes the observations for which no data is available in either of the two databases

-P: indicates the observations where there is a perfect (or close to perfect) match between the data in the sectoral and the data in the summary datasets.

-R: labels the observations where registrations made by residents are missing in the sectoral database, or where the number of registrations made by residents reported in the sectoral database is significantly lower than the number of registrations made by residents reported in the summary database.

-S: codes the observations for which there is information available only in the summary database.

-?: incorporates all the observations that suffer from "other inconsistencies".

The following two codes have also been constructed, to separate those cases where there were missing observations for the whole category of registrations made through the national offices (tncode) and for the whole category of registrations made through the Madrid System (tmcode).

\section{tncode:}


-"OK": There is at least one class with non-zero non-missing entries for registrations made via the national office for that destination-year combination

"tnMiss": data on registrations made through national offices is either zero or missing for that destination-year combination

\section{tmcode:}

"“OK": There is at least one class with non-zero non-missing entries for registrations made under the Madrid System for that destination-year combination

-"tmMiss": data on registrations under the Madrid System is either zero or missing for that destination-year combination

tmcodeSum: A further flag has been created in order to distinguish between the observations relative to the registrations made through the Madrid system that were missing due to a real lack of reporting or, simply, because the country was not a member of either the Madrid Agreement or the Madrid Protocol in that particular year.

- "Miss2": indicates the destination-year combinations for which registrations made through the Madrid system are real missings (e.g. the country is a member and TM registrations are not available at the sectoral level -or the country is a member, TM registrations are not available at the sectoral level but are reported at the summary level).

- "OK2": labels those destination-year combinations where the destination country is not a member of the Madrid System (Agreement or Protocol) and for which registrations are not available ${ }^{27}$.

\footnotetext{
${ }^{27}$ The sectoral database still keeps the following control variables, created to construct the flags described above: sectoraltot (total number of registrations by destination and year from the sectoral file), summarytot (total number of registrations by destination and year from the summary file), error (sectoraltot-summarytot), tm (sum of rtm and rsm, by destination country and year), tn (sum of rtn and rsn, by destination country and year).
} 